\title{
IMPLEMENTASI KUALITAS DAN SIKAPKERJA TERHADAP KINERJA PEGAWAI DAN KEPUASAN PELAYANAN DI KANTOR KECAMATAN SUNGAI PINANG OGAN ILIR
}

\author{
Ellen Suminiarni $^{1)}$, Yun Suprani ${ }^{2)}$, Muhammad Said ${ }^{3)}$ \\ 1,2,3) Dosen jurusan manajemen, Universitas Tridinanit, Palembang, Sumatera Selatan, Indonesia \\ 2)yunsuprani070667@gmail.com
}

\begin{tabular}{l} 
INFORMASI ARTIKEL \\
\hline Submitted: \\
15/12/2021 \\
Revised: \\
29/11/2021 \\
Accepted: \\
15/12/2021 \\
Online-Published: \\
31/12/2021
\end{tabular}

\section{A. PENDAhULUAN}

Salah satu indikator suksesnya pelaksanaan otonomi daerah di bidang pelayanan publik adalah terjadinya perubahan yang lebih baik dalam melayani masyarakat. Pelayanan yang baik seperti di kantorkecamatan sangat dipengaruhi oleh kualitas dan sikap kerja pegawainya. Kualitas kerja merupakan keandalan pegawai dalam melaksanakan tugasnya melayani masyarakat. Dengan kualitas kerja yang baik seorang pegawai akan tepat waktu, cermat dan dapat menyelesaikan tugas yang sesuai dengan prosedur kerja.

Seperti yang dikemukakan oleh (Hao, 2013), kualitas kerja merupakan keandalan dalam melaksanakan tugasnya dan akan tercapai mutu yang tinggi, tepat waktu, cermat dan dengan prosedur yang mudah dipahami. Kualitas kerja sangat diperlukan agar setiap pegawai dapat menjalankan tugasnya dengan baik.Kualitas kerja akan mempengaruhikualitas pelayanan.

Pemerintah membuat kebijaksanaan agar dapat meningkatkan kualitas pelayanan publik. Ada beberapa kebijakan yang telah dikeluarkan pemerintah seperti UndangUndang Republik Indonesia Nomor 22 Tahun 1999 tentang Pemerintahan Daerah yang selanjutnya diubah dengan Undang-Undang Republik Indonesia Nomor 32 Tahun 2004. Undang-undang ini diperbarui lagi menjadi Undang-Undang No. 23 Tahun 2014. Pegawai diarahkan untuk meningkatkan pelayanan terhadap masyarakat. Dengan 
adanya pelimpahan wewenang dari pemerintah pusat ke daerah memungkinkan terjadinya penyelenggaraan pelayanan dengan jalur birokrasi yang lebih ringkas dan membuka peluang bagi pemerintah daerah untuk melakukan inovasi dalam rangka pemberian dan peningkatan kualitas pelayanan kepada masyarakat.

Namun pelayanan masyarakat masih mengalami beberapa kelemahan. Hal ini disebabkan rendahnya kualitas sumber daya manusia.Ombudsman menilai, kualitas pelayanan publik di Indonesia masih sangat kurang. Jika tak ada langkah perbaikan signifikan, target negara ini untuk menggapai tujuh besar ekonomi dunia akan sirna begitu saja.Peringkat pelayanan publik Indonesia saat ini berada di urutan 129 dari 188 negara di dunia. Padahal dalam Undang-undang (UU) Nomor 25 Tahun 2009 mengenai Pelayanan Publik mengamanahkan agar memperkuat komitmen negara dalam mempercepat pelayananpublik(Ariyanti, 2014).

Pengaduan masyarakat terkait pelayan publik yang telah dilakukan penanganan dan penyelesaian oleh Ombudsman sepanjang tahun 2019 mencapai 11.087 aduan. Jumlah ini meningkat dari tahun 2018 yang mencapai 10.985 aduan. Berdasarkan data Ombudsman, tahun 2019, pemerintah daerah menjadi terlapor yang banyak diadukan masyarakat berkaitan dengan pelayanan publik sebanyak 41,03 persen. Instansi kepolisian menduduki peringkat kedua dengan 13,84 persen dan diikuti instansi pemerintah/kementerian dengan 9,87 persen (Dewi, 2020).

Kualitas pelayanan publik yang tidak memuaskan juga terjadi di Kecamatan Sungai Pinang Kabupaten Ogan Ilir. Sikap pegawai yang pasif terhadap pekerjaan merupakan salah satu penghambat pelayanan pada masyarakat. Pekerjaan sering tidak sesuai dengan waktu yang telah ditentukan. Masyarakat menilai ada kesenjangan pemberian pelayanan.Bagi masyarakat yang memiliki status sosial lebih tinggi, mereka lebih cepat dilayani. Sedang masyarakat menengah ke bawah lebih lambat dilayani.

Pelayanan yang baik terutama di sektor pelayanan publik seperti kantor Kecamatan Sungai Pinang sangat dipengaruhi oleh kualitas dan sikap kerja pegawainya. Kualitas kerja merupakan keandalan pegawai dalam melaksanakan tugasnya melayani masyarakat.Dengan kualitas kerja yang baik seorang pegawai akan tepat waktu, cermat dan dapat menyelesaikan tugas yang sesuai dengan prosedur kerja. Sikap berkaitan erat dengan perilaku..Sikap seorang pegawai dapat diamati secara langsung, seperti pegawai yang marah kalau pekerjaan bertumpuk, atau pegawai yang sering tidak hadir untuk menghindari pekerjaan.

\section{B. METODE PENELITIAN}

Salah satu indikator suksesnya pelaksanaan otonomi daerah di bidang pelayanan publik adalah terjadinya perubahan yang lebih baik dalam melayani masyarakat. Pelayanan yang baik seperti di kantorkecamatan sangat dipengaruhi oleh kualitas dan sikap kerja pegawainya. Kualitas kerja merupakan keandalan pegawai dalam melaksanakan tugasnya melayani masyarakat. Dengan kualitas kerja yang baik seorang pegawai akan tepat waktu, cermat dan dapat menyelesaikan tugas yang sesuai dengan prosedur kerja.

Seperti yang dikemukakan oleh (Hao, 2013), kualitas kerja merupakan keandalan dalam melaksanakan tugasnyadan akan tercapai mutu yang tinggi, tepat waktu, cermat dan dengan prosedur yang mudah dipahami.Kualitas kerja sangat diperlukan agar setiap pegawai dapat menjalankantugasnya dengan baik.Kualitas kerja akan mempengaruhikualitas pelayanan.

Pemerintah membuat kebijaksanaan agar dapat meningkatkan kualitas pelayanan publik. Ada beberapa kebijakan yang telah dikeluarkan pemerintahseperti UndangUndang Republik Indonesia Nomor 22 Tahun 1999 tentang Pemerintahan Daerah yang selanjutnya diubah dengan Undang-Undang Republik Indonesia Nomor 32 Tahun 2004. Undang-undang ini diperbarui lagi menjadi Undang-Undang No. 23 Tahun 2014.Pegawai diarahkan untuk meningkatkan pelayanan terhadap masyarakat. Dengan adanya pelimpahan wewenang dari pemerintah pusat ke daerah memungkinkan terjadinya penyelenggaraan pelayanan dengan jalur birokrasi yang lebih ringkas dan membuka peluang bagi pemerintah daerah untuk melakukan inovasi dalam rangka pemberian 
dan peningkatan kualitas pelayanan kepada masyarakat.

Namun pelayanan masyarakat masih mengalami beberapa kelemahan. Hal ini disebabkan rendahnya kualitas sumber daya manusia.Ombudsman menilai, kualitas pelayanan publik di Indonesia masih sangat kurang. Jika tak ada langkah perbaikan signifikan, target negara ini untuk menggapai tujuh besar ekonomi dunia akan sirna begitu saja.Peringkat pelayanan publik Indonesia saat ini berada di urutan 129 dari 188 negara di dunia. Padahal dalam Undang-undang (UU) Nomor 25 Tahun 2009 mengenai Pelayanan Publik mengamanahkan agar memperkuat komitmen negara dalam mempercepat pelayananpublik(Ariyanti, 2014).

Pengaduan masyarakat terkait pelayan publik yang telah dilakukan penanganan dan penyelesaian oleh Ombudsman sepanjang tahun 2019 mencapai 11.087 aduan.Jumlah ini meningkat dari tahun 2018 yang mencapai 10.985 aduan. Berdasarkan data Ombudsman, tahun 2019, pemerintah daerah menjadi terlapor yang banyak diadukan masyarakat berkaitan dengan pelayanan publik sebanyak 41,03 persen. Instansi kepolisian menduduki peringkat kedua dengan 13,84 persen dan diikuti instansi pemerintah/kementerian dengan 9,87 persen (Dewi, 2020).

Kualitas pelayanan publik yang tidak memuaskan juga terjadi di Kecamatan Sungai Pinang Kabupaten Ogan Ilir. Sikap pegawai yang pasif terhadap pekerjaan merupakan salah satu penghambat pelayanan pada masyarakat. Pekerjaan sering tidak sesuai dengan waktu yang telah ditentukan.Masyarakat menilai ada kesenjangan pemberian pelayanan.Bagi masyarakat yang memiliki status sosial lebih tinggi, mereka lebih cepat dilayani. Sedang masyarakat menengah ke bawah lebih lambat dilayani.

Pelayanan yang baik terutama di sektor pelayanan publik seperti kantor Kecamatan Sungai Pinang sangat dipengaruhi oleh kualitas dan sikap kerja pegawainya. Kualitas kerja merupakan keandalan pegawai dalam melaksanakan tugasnya melayani masyarakat.Dengan kualitas kerja yang baik seorang pegawai akan tepat waktu, cermat dan dapat menyelesaikan tugas yang sesuai dengan prosedur kerja. Sikap berkaitan erat dengan perilaku..Sikap seorang pegawai dapat diamati secara langsung, seperti pegawai yang marah kalau pekerjaan bertumpuk, atau pegawai yang sering tidak hadir untuk menghindari pekerjaan.

\subsection{Hubungan antara Kualitas dan Sikap Kerja terhadap Kinerja Pegawai}

Kaitan antara kualitas dan Sikap Kerja Pegwai terhadap Kinerja pegawai adalah, kualitas pelayanan yang diberikanpegawai harusmemenuhi kebutuhan masyarakat yang optimal sesuai dengan standar yang diberikan pemerintah. Kepuasan masyarakat juga dipengaruhi oleh kinerja pegawai. Kinerja pegawai merupakan tolok ukur pada kantor pemerintah. Pegawai yang memiliki Kualitas dan sikap kerja yang baik terhadap tugas dan tanggung jawabnyapasti akan menjalankan tugasnya dengan baik.

\subsection{Hubungan antara Kualitas dan Sikap Kerja terhadapKinerja Pegawai dan Kepuasan Pelayanan}

Kualitas dan Sikap kerja yang baik di suatu instansi pelayanan akan memudahkan instansi tersebut memberikan kualitas pelayanan yang baik pada masyarakat.Pendapat sesuai dengan teori (Hasibuan, 2013). Kepuasan masyarakat adalah perasaan senang atau kecewa setelah membandingkan antara persepsi terhadap kinerja dan harapannya. Keberhasilan instansi pemerintahan dapat dilihat bila pegawainya dapat memberikan pelayanan yang baiksehingga masyarakat menjadi puas. Model hipotesis dalam penelitian ini dapat dilihat pada Gambar 1

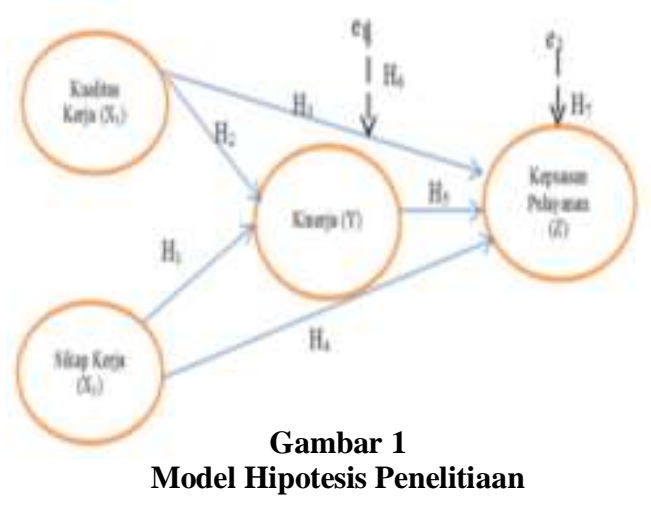

Keterangan

$\mathrm{H}_{1}$ : Kualitas Kerja berpengaruh signifikan terhadap Kinerja Pegawai 
$\mathrm{H}_{2}$ : Sikap Kerja berpengaruh signifikan terhadap Kinerja Pegawai

$\mathrm{H}_{3}:$ Kualitas Kerja berpengaruh signifikan terhadap Kepuasan Pelayanan.

$\mathrm{H}_{4}$ : Sikap Kerja berpengaruh signifikan terhadap Kepuasan Pelayanan.

$\mathrm{H}_{5}$ :Kinerja berpengaruh signifikan terhadap Kepuasan Pelayanan

$\mathrm{H}_{6}$ : Kualitas Kerja berpengaruh secara tidak langsung terhadap Kepuasan Pelayanan melalui Kinerja Pegawai pada Kantor Kecamatan Sungai Pinang Kabupaten Ogan Ilir

$\mathrm{H}_{7}$ : Sikap Kerja berpengaruh secara tidak langsung terhadap Kepuasan Pelayanan melalui Kinerja Pegawai pada Kantor Kecamatan Sungai Pinang Kabupaten Ogan Ilir

Model persamaan analisis jalur pada penelitian ini adalah sebagai berikut:

$\mathrm{Y}=P y X_{1}+P y X_{2}+\mathrm{e}_{1}$

$\mathrm{Z}=P z X_{1}+P z X_{2}+P z Y+\mathrm{e}_{2}$

Keterangan:

$\mathrm{X}_{1}=$ Kualitas Kerja

$\mathrm{Y}=$ Kinerja

$\mathrm{Z}=$ Kepuasan Pelayanan

$\mathrm{X}_{2}=$ Sikap Kerja

C. HASIL DAN PEMBAHASAN

Hasil Penelitian Analisis Jalur (Path Analysis)

1. Persamaan Sub Struktural 1

Tabel 1. Persamaan Regresi Berganda Sub Struktural 1

\begin{tabular}{|c|c|c|c|c|c|}
\hline & \multicolumn{3}{|c|}{ Coefficients $^{a}$} & \multirow[b]{3}{*}{$t$} & \multirow[b]{3}{*}{ Sig. } \\
\hline \multirow[b]{2}{*}{ Model } & \multicolumn{2}{|c|}{$\begin{array}{l}\text { Unstandardized } \\
\text { Coefficients }\end{array}$} & \multirow{2}{*}{$\begin{array}{c}\begin{array}{c}\text { Standard } \\
\text { ized } \\
\text { Coefficie } \\
\text { nts }\end{array} \\
\text { Beta } \\
\end{array}$} & & \\
\hline & B & $\begin{array}{l}\text { Std. } \\
\text { Error }\end{array}$ & & & \\
\hline $1 \quad$ (Constant & 10,994 & 3,646 & & 3,016 & ,004 \\
\hline $\begin{array}{l}\text { Kualitas } \\
\text { Kerja }\end{array}$ & 215 & 100 & ,279 & 2,145 & ,037 \\
\hline $\begin{array}{l}\text { Sikap } \\
\text { Kerja }\end{array}$ & ,412 & , 129 & ,416 & 3,200 & ,002 \\
\hline
\end{tabular}

\section{Pengaruh langsung Kualitas Kerja} terhadap Kinerja

Pada Tabel 1 di atas, diketahui bahwa nilai $t_{\text {hitung }}$ lebih besar daripada $t_{\text {tabel }}$
$(2,176>1,676)$ dengan nilai Sig. 0,037 yang berarti lebih kecil daripada 0,05. Dan besarnya koefisien Beta Jalur variabel kualitas $\operatorname{kerja}\left(\mathrm{X}_{1}\right)$ terhadap kinerja pegawai $(\mathrm{Y})$ adalah 0,279 $\left(\rho \mathrm{YX}_{1}\right)$. Berarti pengaruh kualitas kerja pegawai Kantor kecamatan Sungai Pinang Ogan Ilir terhadap Kinerjanya dalam kategori sedang.Sehingga hipotesis diterima. Kesimpulannya, bahwa ada pengaruh langsung dan signifikan antara kualitas kerja terhadapkinerja.

\section{Persamaan Sub Struktural 2}

Tabel 2. Persamaan Regresi Berganda Sub Struktural 2

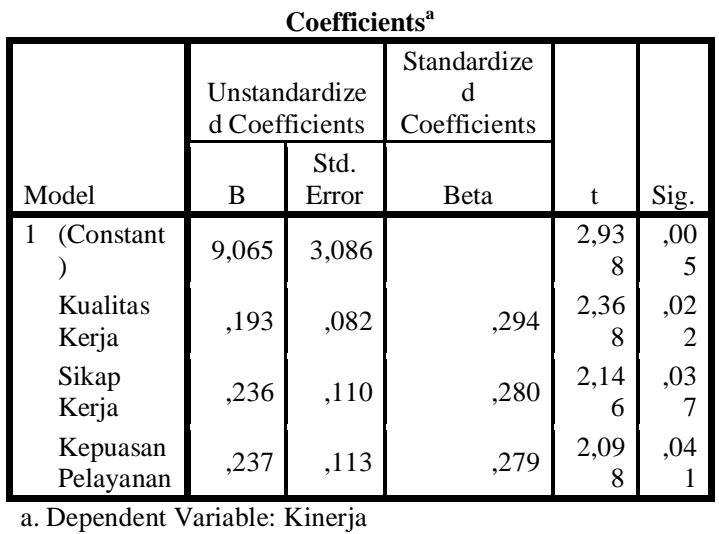

Pengaruh langsung Kualitas Kerja terhadap Kepuasan Pelayanan

Berdasarkan Tabel 2 di atas, diketahui bahwa nilai $t_{\text {hitung }}$ lebih besar daripada $t_{\text {tabel }}(2,368>1,676)$ dengan nilai Sig. 0,022 yang berarti lebih kecil daripada 0,05. Dan besarnya koefisien Beta Jalur variabel Kualitas $\operatorname{Kerja}\left(\mathrm{X}_{1}\right)$ terhadap Kepuasan Pelayanan (Z) adalah 0,279 $\left(\rho Z_{1}\right)$. Koefisien jalur lebih kecil dari 0,30 yang berarti kategori pengaruh kualitas Kerja terhadap Kualitas Pelayanan termasuk sedang. Artinya hipotesis diterima, dan .kesimpulannya, terdapaat pengaruh langsung dan signifikan antara Kualitas Kerja terhadap Kualitas Pelayanan yang berarti hipotesis ketiga atau diterima

\section{Pengaruh langsung Sikap Kerja terhadap Kualitas Pelayanan}

Berdasarkan Tabel 2 di atas, diketahui bahwa nilai $t_{\text {hitung }}$ lebih besar daripada $t_{\text {tabel }}(2,146>1,676)$ dengan nilai 
Sig. 0,037, lebih kecil daripada 0,05. Dan besarnya koefisien Beta Jalur variabel Sikap Kerja(Y) terhadap Kualitas Pelayanan (Z) adalah $0,280(\rho \mathrm{ZY})$. Di mana koefisien jalur lebih rendah dari 0,30 yang berarti kategori daya atau pengaruh Sikap Kerjaterhadap Kualitas Pelayanansedang. Artinya hipotesis diterima. Kesimpulannya, bahwa ada pengaruh langsung dan signifikan antara Sikap KerjaterhadapKualitas Pelayanan yang berarti hipotesis kelima diterima.

Tabel 3. Kesimpulan Hasil Analisis

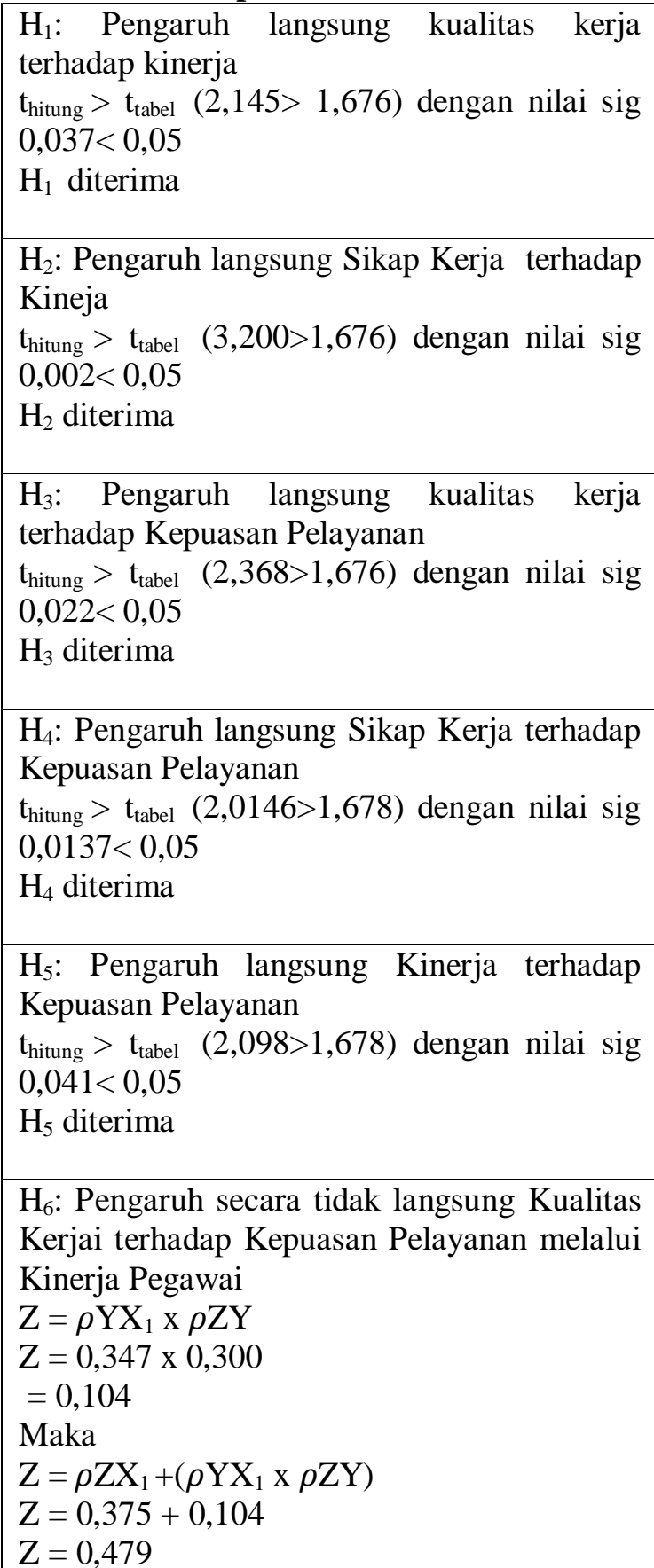

$4,77>1,96$

H6 ditolak

$\mathrm{H}_{7}$ : Pengaruh secara tidak langsung Sikap Kerja terhadap Kepuasan Pelayanan melalui Kinerja Pegawai

$\mathrm{Z}=\rho \mathrm{YX}_{2} \mathrm{x} \rho \mathrm{ZY}$

$\mathrm{Z}=0,333 \times 0,320$

$=0,0106$

Maka

$\mathrm{Z}=\rho \mathrm{ZX}_{2}+\left(\rho \mathrm{YX} \mathrm{X}_{2} \mathrm{x} \rho \mathrm{ZY}\right)$

$Z=0,254+0,106$

$\mathrm{Z}=0,361$

$2,598>1,96$

H7 diterima

\section{SIMPULAN DAN SARAN Simpulan}

Seorang pegawai harus memiliki Kualitas dan Sikap Kerja yang baik dalam melaksanakan tugasnya melayani masyarakat.Kualitas kerja pegawai ditunjukkan dengan ketepatan waktu dan cermat dalam menyelesaikan tugas dan sesuai dengan prosedur kerja.

Dengan kualitas dan sikap kerja yang handal, seorang pegawaidapat memberikan konstribusi kepada organisasi.Kinerja seorang pegawai dapat diukur dengan seberapa banyak kuantitas, kualitas kerja yang dapat diselesaikan seorang pegawai.Selain itu, sikap pegawai dan konsistensinya dalam menyelesaikan pekerjaan juga perlu diperhatikan.

Banyak hasil penelitian mengenai kualitas pelayanan pegawai pada kantor pemerintahan. Seperti penelitian yang dilakukan Rukaya tmengenai Kualitas Pelayanan Publik Bidang Adminstrasi Kependudukan di Kecamatan Pasir Jambu.Hasil penelitiannya menunjukkan bahwa kualitas pelayanan publik bidang administrasi kependudukan di Kecamatan Pasirjambu yaitu bagian Pelayanan Umum belum memberikan pelayanan yang baik kepada masyarakat. Namun, masyarakat merasa puas dengan pelayanan dalam aspek reliability yaitu kehandalan dalam menangani setiap keluhan masyarakat.

Hasil penelitian kualitas dan sikap kerja terhadap kinerja dan kepuasan 
pelayanan di Kecamatan Sungai Pinang Ogan Ilir menunjukkan hasil koefisien jalur antarvariabel daya pengaruhnya di interval sedang. Artinya, kualitas pelayanan di kantor ini harus lebih ditingkatkan lagi. Kinerja pegawai dalam melayani masyarakat harus ditingkatkan lagi.

\section{E. DAFTAR RUJUKAN}

Ariyanti, F. (2014). No Title. Pelayanan Publik Indonesia Di Urutan 129. https://www.liputan6.com/bisnis/read/2 079787/pelayanan-publik-indonesia-diurutan-129

br Sembiring, D. (2019). Pengaruh Sikap Kerja Dan Motivasi Kerja Terhadap Kinerja Dosen Di Yayasan Perguruan Nasional Medicom. Jurnal Teknik Informatika UNIKA Santo Thomas, 3(2), 108-118.

Dewi, R. S. (2020). No Title. Proyeksi Peningkatan Kualitas Pelayanan Publik 2020.

https://ombudsman.go.id/artikel/r/artike 1--proyeksi-peningkatan-kualitaspelayanan-publik-2020

Hao, L. (2013). Pelaksanaan Reformasi Birokrasi Dalam Meningkatkan Kualitas Kerja Pegawai Di Kantor Pertanahan Kota Banjar. Skripsi, Hal, 3-11.

Hasibuan, M. (2013). Manajemen Sumber Daya Manusia Cetakan Ketujuh Belas. Jakarta: Bumi Aksara.

Ivancevich John, M., Robert, K., \& Matteson Michael, T. (2006). Perilaku dan manajemen organisasi. Erlangga, Jakarta.

Rukayat, Y. (2017). Kualitas pelayanan publik bidang administrasi kependudukan di kecamatan pasirjambu. Jurnal Ilmiah Magister Administrasi, 11(2). 